\title{
RANCANG BANGUN SISTEM INFORMASI HOLTICULTURAL OLAT MARAS BERBASIS WEB
}

\author{
Eri Sasmita Susanto ${ }^{1 *}$, M. Zammul Aditya Fu'ani ${ }^{2}$ \\ 1,2,Teknik Informatika, Universitas Teknologi Sumbawa \\ email: eri.sasmita.susanto@uts.ac.id*
}

\begin{abstract}
Abstrak: Olat Maras Holticultural merupakan organisasi yang berada dilingkungan Universitas Teknologi Sumbawa dibentuk untuk melakukan pembudidayaan terhadap berbagai jenis tanaman. Dalam melakukan pendataan dan pelaporan masih menggunakan cara manual. Proses pemesanan atau pembayaran bibit kurang efisien waktu karena tidak dilakukan oleh sistem. Solusi dari permasalah yang terjadi pada Olat Maras Holticultural adalah menerapkan teknologi informasi dengan cara membangun sebuah sistem informasi atau aplikasi yang memudahkan petugas dalam mengelola data bibit dan kemudahan dalam melakukan transaksi. Maka tujuan dari penelitian ini adalah membangun Sistem Informasi Olat Maras Holticultural Berbasis Web. Sistem ini dibangun menggunakan bahasa pemrogramman PHP dengan menggunakan Framework Bootstrap dan MySql sebagai database. Metode yang digunakan dalam membangun sistem ini adalah menggunakan metode Waterfall. Sistem atau aplikasi ini diharapkan dapat mempermudah dan mempercepat proses pengelolaan data bibit, pelaporan serta proses transaksi.
\end{abstract}

Kata Kunci : Olat Maras Holticultural, Sistem Informasi, Jual Beli Bibit, Waterfall.

\begin{abstract}
Olat Maras Holticultural is an organization located in the University of Technology Sumbawa which formed to cultivate various types of plants. In collecting seed data and making reports, they are still use manual methods. The seed ordering or payment process is consume the time too much because it is not computerized yet. The solution to the problems that occur in Olat Maras Holticultural is to apply information technology by building an information system or application that makes it easier for the staff to manage seed data and ease in conduction transactions. So, the purpose of this research is to build a Web-Based Olas Maras Holticultural Information System. This system is built by using PHP as the programming language, Bootstrap as the Framework and MySql as the database. The method that used in building this system is Waterfall method. This system or application is expected to make the process easier in managing seed data, making reports and transaction processes.
\end{abstract}

Key Word: Olat Maras Holticultural, Information System, Seed Transaction, Waterfall.

\section{PENDAHULUAN}

Latar Belakang

Reboisasi merupakan kegiatan penghijauan atau menanam pohon kembali pada suatu kawasan, wilayah, maupun lahan yang kurang terhadap pepohonan. Tujuan dari kegiatan reboisasi ini adalah agar kelestarian alam sekitar tetap terjaga dan mencegah terjadinya bencana alam seperti banjir dan longsor yang diakibatkan oleh penggundulan hutan. Kegiatan melestarikan alam juga dapat dilakukan melalui reservasi holticultural.

Holticultural adalah cabang ilmu yang mempelajari tentang pembudidayaan pepohonan, bunga, sayuran, dan buah-buahan. Olat Maras Holticultural merupakan salah satu organisasi yang berada di kawasan Universitas Teknologi Sumbawa yang bertujuan untuk melestarikan kawasan alam sekitar dengan melakukan budidaya terhadap pepohonan untuk kemudian ditanam kembali. Sampai saat ini Olat Maras Holticultural belum memiliki sistem khusus dalam hal melakukan pendataan maupun penjualan. Pendataan masih dilakukan dengan cara manual dan untuk membuat laporan biasanya menggunakan Microsoft Excel ataupun Google Sheet. Proses penjualan pun masih sulit karena transaksi dilakukan secara konvensional, penjual dan pembeli harus bertemu secara langsung untuk melakukan pembayaran.

Berdasarkan permasalahan tersebut maka penulis berinisiatif untuk merancang dan membangun sistem informasi pada Olat Maras Holticultural berbasis web untuk mengatasi permasalahan yang terjadi. Sistem informasi ini dibagi menjadi 2 (dua) level users. Aplikasi tersebut dapat digunakan oleh staf sebagai admin yang bertugas melakukan pendataan dan member yang ingin membeli atau memesan bibit. Pendataan yang dilakukan meliputi jumlah bibit, jenis bibit, tahun masuk dan tahun keluar. Bentuk pelaporan dari sistem informasi ini berupa file pdf dan tampilan grafik atau diagram hasil dari penjualan.

Dengan dibangun sistem informasi Olat Maras Holticultural tersebut diharapkan mampu untuk membuat proses yang dilakukan menjadi lebih mudah, baik dalam melakukan pendataan dan pelaporan bagi admin Olat Maras Holticultural maupun proses transaksi dan pemesanan bibit bagi pelanggan. adalah :

Adapun tujuan dari dilakukannya penelitian ini

1. Menjadikan pekerjaan petugas Olat Maras Holticultural menjadi lebih mudah dengan 
dibangunnya sistem informasi dalam melakukan pendataan terhadap pembibitan yang dilakukan.

2. Membuat proses pelaporan hasil pembibitan menjadi lebih baik dari sebelumnya, sehigga admin dari sistem informasi ini nantinya tidak lagi membuat pelaporan menggunakan Microsoft Excel ataupun Google Sheet.

3. Menyediakan layanan untuk melakukan pemesanan dan pembelian bibit pada Olat Maras Holticultural.

\section{TINJAUAN PUSTAKA}

\section{Rancang Bangun}

Menurut Pressman (2010 :39) rancang bangun merupakan hasil analisa dari sebuah sistem yang diterjemahkan ke dalam bahasa pemrograman yang kemudian diimplementasikan berdasarkan dari komponen-komponen yang telah dideskripsikan sebelumnya.

Sedangkan menurut pendapat Ladjamudin (2013 :39), bahwa perancangan adalah kegiatan mendesain sebuah sistem yang diperoleh dari pemilihan sistem yang terbaik untuk menyelesaikan masalah yang sedang dihadapi sebuah instansi ataupun perusahaan.

Berdasarkan pendapat para ahli diatas dapat disimpulkan bahwa rancang bangun dapat didefinisikan sebagai suatu kegiatan berupa implementasi dari hasil analisa yang dilakukan pada sebuah sistem ke dalam sebuah software (perangkat lunak) dengan tujuan untuk menciptakan suatu sistem baru atau memperbaiki sistem yang sudah ada.

\section{Sistem Informasi}

Menurut Mulyani (2016:2) pengertian sistem informasi merupakan perpaduan antara perangkat lunak, perangkat keras dan jaringan komunikasi sehingga menghasilkan sebuah data yang berguna.

Sedangkan menurut pendapat Kadir (2016 :8) menyatakan bahwa sistem informasi adalah kumpulan perintah formal yang mengelompokkan data untuk diproses menjadi informasi agar dapat didistribusikan.

Berdasarkan pendapat para ahli diatas maka dapat disimpulkan bahwa sistem informasi merupakan kumpulan elemen yang dikelompokkan yang kemudian diproses dan diolah menjadi sebuah informasi yang berguna.

\section{Web}

Menurut Solusindo (2008 :7) web adalah sebuah situs yang di hosting yang kemudian dapat diakses melalui mesin pencarian dengan menggunakan domain tertentu.
Sedangkan pendapat yaitu Solichin (2016:3) bahwa web merupakan server web yang memiliki fungsi untuk menerima permintaan klien dan kemudian mengirimkan hasilnya melalui sebuah protocol Hyper Text Transfer Protocol (HTTP) ataupun Hyper Text Transfer Protokol Secure (HTTPS).

\section{METODE}

Penelitian ini menggunakan metode kualitatif. Menurut pendapat Sugiyono (2013:15) kualitatif adalah metode penelitian yang bersifat memberikan penjelasan dengan menggunakan teknik analisa. Pada pelaksanaannya, metode kualitatif bersifat subjektif dimana proses penelitian lebih cenderung dan memiliki titik fokus pada landasan teori.

Adapun alur penelitian pada penelitian ini dapat dilihat pada gambar berikut:

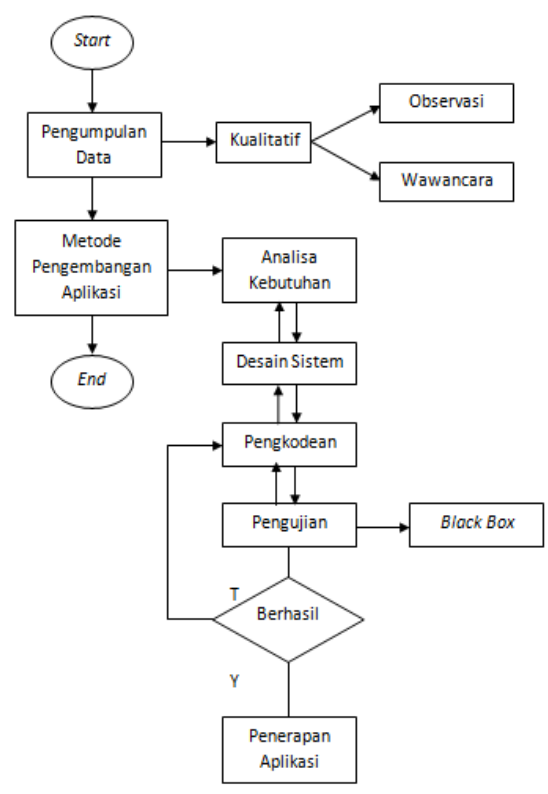

Gambar 1. Alur Penelitian

\section{Metode Pengumpulan Data}

Pada tahapan ini penulis mengumpulkan data dengan menggunakan metode observasi dan wawancara. Masing-masing metode tersebut akan dijelaskan sebagai berikut:

1. Observasi

Pada tahap ini penulis melakukan pengamatan untuk mendapatkan gambaran umum terhadap permasalahan yang terjadi. Pengamatan tersebut dilakukan dengan mendatangi langsung ruangan direktur Olat Maras Holticultural dan lahan tempat melakukan pembibitan. 
2. Wawancara

Penulis melalukan tanya jawab dan diskusi dengan bapak Muhammad Ardiansyah,SEI selaku Direktur terkait dengan informasi yang dibutuhkan mengenai Olat Maras Holticultural. Adapun hasil dari diskusi dan wawancara yang dilakukan akan dicantumkan pada bagian lampiran di penelitian ini.

\section{Studi Pustaka}

Pada tahap ini penulis mempelajari konsep, teknik maupun informasi yang dibutuhkan dengan cara mengumpulkan atau mencari dari berbagai sumber seperti internet, buku, jurnal ataupun artikel ilmiah lainnya yang berkaitan dengan sistem informasi yang akan dibangun.

\section{Metode Pengembangan Perangkat Lunak}

Adapun metode pengembangan perangkat lunak yang digunakan yaitu metode waterfall, menurut Rosa dan Shalahudin (2013 :28) sebagai berikut:

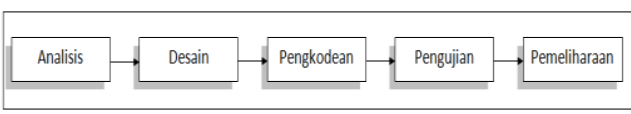

Gambar 2. Metode Waterfall

Adapun tahapan-tahapan metode waterfall dari gambar diatas dijabarkan sebagai berikut:

1. Analisis

Tahap analisis dilakukan secara intensif untuk menspesifikasikan kebutuhan sistem agar dapat dipahami sistem seperti apa yang dibutuhkan oleh user.

\section{Desain}

Tahap desain adalah proses multi langkah yang fokus pada desain pembuatan program sistem termasuk struktur data, arsitektur sistem, representasi antarmuka, dan prosedur pengodean. Tahap ini mentranslasi kebutuhan sistem dari tahap analisis kebutuhan ke representasi desain agar dapat di implementasikan menjadi program pada tahap selanjutnya.

\section{Pengkodean}

Pada tahap pengodean, desain harus ditranslasikan ke dalam program sistem. Hasil dari tahap ini adalah program yang sesuai dengan desain yang telah dibuat pada tahap desain.

\section{Pengujian}

Tahap pengujian fokus pada sistem dari segi logika dan fungsional dan memastikan bahwa semua bagian sudah diuji. Hal ini dilakukan untuk meminimalisir kesalahan (error) dan memastikan keluaran yang dihasilkan sesuai dengan yang diinginkan.

\section{Pemeliharaan}

Pemeliharaan dilakukan apabila sebuah sistem mengalami perubahan ketika sudah dikiriman ke user. Perubahan 210ias terjadi karena adanya kesalahan yang muncul dan tidak terdeteksi saat pengujian atau sistem harus beradaptasi dengan lingkungan baru. Tahap pemeliharaan dapat mengulangi proses pengembangan mulai dari analisis spesifikasi untuk perubahan sistem yang sudah ada, tapi tidak untuk sistem baru.

\section{HASIL DAN PEMBAHASAN Alur Kerja Sistem}

Berdasarkan permasalahan yang telah dipaparkan sebelumnya maka penulis mengusulkan sebuah alur kerja sistem yang baru pada Olat Maras Holticultural sebagai berikut:

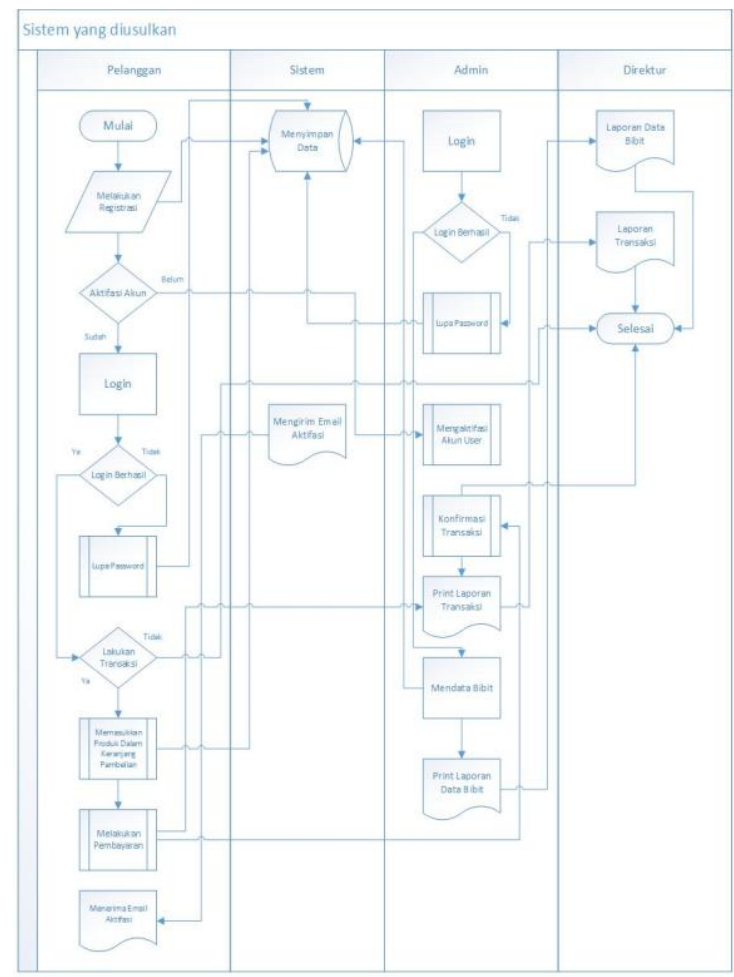

Gambar 3. Alur Kerja Sistem Usulan

\section{Use Case Diagram}

Use case diagram menjelaskan aktor mana saja yang terlibat langsung dengan sistem, dan apa saja yang dapat dilakukan. Adapun use case pada penelitian ini adalah sebagai berikut:

Berikut adalah gambar use case admin: 


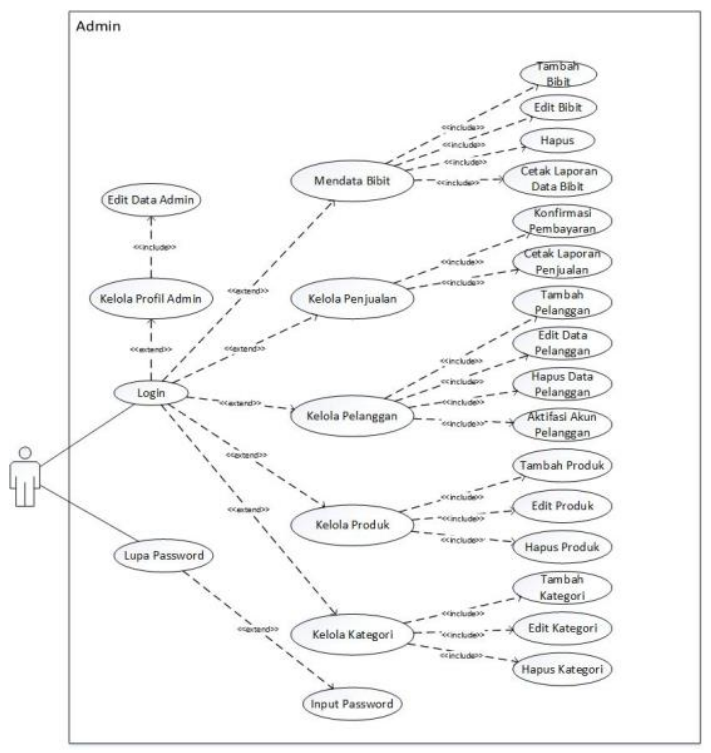

Gambar 4. Use Case Admin

\section{Activity Diagram}

Diagram aktifitas pada penelitian ini akan menggambarkan aliran kerja yang terdapat pada sistem. Berikut adalah activity diagram yang terdapat pada sistem informasi ini:

\section{Activity Login Admin}

Berikut adalah activity diagram pada proses login admin:

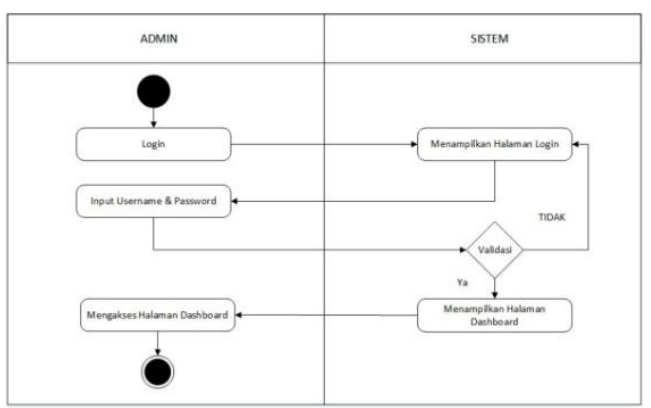

Gambar 5. Activity Login Admin

2. Activity Input Data Bibit

Berikut adalah activity proses input data bibit pada sistem ini:

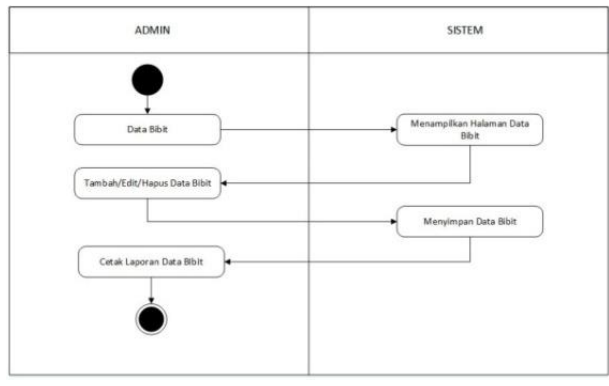

Gambar 6. Activity Input Data Bibit

\section{Implementasi Program}

Berikut adalah implementasi dari Sistem Informasi Olat Maras Holticultural:

1. Tampilan Login

Berikut ini merupakan implementasi dari tampilan halaman login:

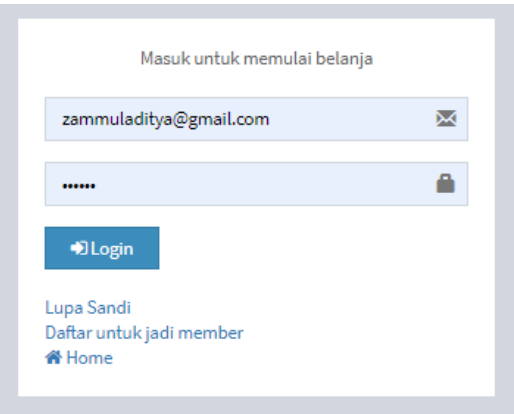

Gambar 7. Tampilan Login

2. Tampilan Dashboard

Berikut adalah implementasi dari tampilan halaman dashboard:

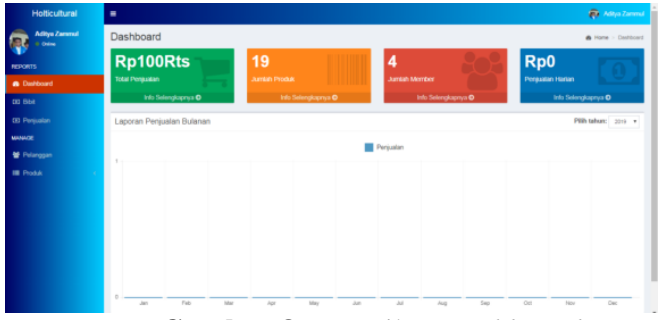

Gambar 8. Tampilan Dashboard

\section{Pengujian Sistem}

Pengujian yang dilakukan terhadap sistem yang dibangun pada penelitian ini adalah menggunakan metode black-box. Berikut beberapa pegujian sistem pada penelitian ini:

1. Uji Halaman Registrasi

Berikut adalah pengujian yang dilakukan pada halaman registrasi.

Tabel 1. Uji Halaman Registrasi

\begin{tabular}{|c|c|c|c|}
\hline No & Aksi & Reaksi & Hasil \\
\hline 1 & Mengosongkan & pesan & \multirow{2}{*}{ OK } \\
& semua field & "Mohon & \\
& & field diisi" & \\
\hline 2 & Hanya mengisi & Muncul & \multirow{2}{*}{ OK } \\
& sebagian field & pesan & \\
\hline
\end{tabular}




\begin{tabular}{|c|c|c|c|}
\hline & & "Mohon & \\
& & field diisi" & \\
& Mengisi field & dan & \\
& dengan & pengguna & OK \\
& lengkap & menerima & \\
& & email & \\
& & aktifasi & \\
\hline
\end{tabular}

2. Uji Halaman Produk

Berikut ini adalah pengujian yang dilakukan pada halaman produk:

Tabel 2. Uji Halaman Produk

\begin{tabular}{|c|c|c|c|}
\hline No & Aksi & Reaksi & Hasil \\
\hline 1 & $\begin{array}{l}\text { Menekan } \\
\text { tombol } \\
\text { new }\end{array}$ & $\begin{array}{l}\text { Menambah data } \\
\text { produk pada } \\
\text { sistem }\end{array}$ & OK \\
\hline 2 & $\begin{array}{l}\text { Menekan } \\
\text { tombol } \\
\text { search } \\
\text { pada } \\
\text { kolom } \\
\text { pencarian }\end{array}$ & $\begin{array}{l}\text { Menampilkan } \\
\text { data produk } \\
\text { yang dicari }\end{array}$ & OK \\
\hline 3 & $\begin{array}{l}\text { Menekan } \\
\text { tombol } \\
\text { view }\end{array}$ & $\begin{array}{l}\text { Menampilkan } \\
\text { detail deskripsi } \\
\text { tentang produk }\end{array}$ & $\mathrm{OK}$ \\
\hline 4 & $\begin{array}{l}\text { Menekan } \\
\text { tombol } \\
\text { edit }\end{array}$ & $\begin{array}{l}\text { Memperbaharui } \\
\text { data produk } \\
\text { yang tersimpan } \\
\text { dalam sistem }\end{array}$ & $\mathrm{OK}$ \\
\hline 5 & $\begin{array}{l}\text { Menekan } \\
\text { tombol } \\
\text { hapus }\end{array}$ & $\begin{array}{c}\text { Menghapus data } \\
\text { produk yang }\end{array}$ & OK \\
\hline
\end{tabular}

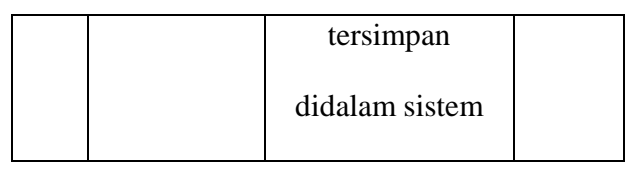

\section{KESIMPULAN DAN SARAN Kesimpulan}

Berdasarkan analisis dan perancangan yang dilakukan maka dapat disimpulkan bahwa penelitian ini telah menghasilkan sebuah sistem informasi berbasis web yang dibangun dengan menggunakan bahasa pemrograman PHP dan menggunakan database MySQL. Sistem Informasi yang dibangun diberi nama Olat Maras Holticultural dan dibangun untuk mempermudah segala aktifitas yang berkatian dengan pendataan bibit, pelaporan dan proses jual beli.

\section{Saran}

Berdasarkan sistem yang dibangun, penulis mempunyai beberapa saran yang mungkin dapat mempermudah proses pengembangan yang akan dilakukan selanjutnya :

1. Dalam pengembangan selanjutnya diharapkan proses aktifasi akun langsung dapat dilakuan oleh pelanggan tanpa harus melalui admin.

2. Pendataan bibit tidak terlalu spesifik, sehingga untuk pengembangan selanjutnya diharapkan pada pendataan bibit tersebut terdapat data usia bibit (bibit siap tanam) serta laporan data bibit yang gagal atau rusak sehingga dengan demikian petugas Olat Maras Holticultural dapat mengambil keputusan dengan mudah.

\section{DAFTAR PUSTAKA}

[1] A. S., Rosa dan Shalahuddin, M. 2013. Rekayasa Perangkat Lunak Terstruktur Dan Berorientasi Objek. Informatika. Bandung.

[2] Andika, Firda. 2014. Sistem Informasi Jual Beli Bibit Tanaman Pada Unit Usaha Pertanian Daerah Lhokseumawe. Universitas Gajah Mada. Jakarta.

[3] Kadir, Abdul. 2013. Pengenalan Sistem Informasi Edisi Revisi.Yogyakarta: Andi Offset.

[4] Ladjamudin, Al-Bahra .2013. Analisis dan Desain Sistem Informasi. Graha Ilmu. Yogyakarta.

[5] Mulyani, Sri. 2016. Metode Analisis dan Perancangan Sistem. Bandung: Abdi Sistematika. 
[6] Nining Lestari, Rizka. 2014. Sistem Informasi Penjualan dan Pemesanan Benih dan Bibit Pada UD. Tanjung Harapan. Universitas Komputer Indonesia. Sumedang.

[7] Roger S., Pressman. 2010. Rekayasa Perangkat Lunak : Pendekatan Praktisi. Andi. Yogyakarta.

[8] Solichin, Ahmad. 2016. Pemrograman Web dengan PHP dan MySQL.Universitas Budi Luhur. Jakarta.

[9] Solusindo, E-Media. 2008. Membangun Komunitas Online Secara Praktis Dan Gratis. Jakarta. : Elex Media Komputindo.

[10] Sugiyono. 2013. Metode Penelitian Kuantitatif Kualitatif dan R \& D. Alfabeta. Bandung. 